\title{
Evaluation of clinico-epidemiological factors and outcome of COVID-19 disease in perinatal period
}

\author{
Suchita V. Dabhadkar, Vaishali S. Taralekar, Mahima R. Arya*, Salil D. Barsode, \\ Pooja S. Kale
}

Department of Obstetrics and Gynecology, Bharati Vidyapeeth (DTU) and Medical College, Pune, Maharashtra, India

Received: 20 January 2021

Revised: 07 March 2021

Accepted: 08 March 2021

\section{*Correspondence:}

Dr. Mahima R. Arya,

E-mail: aryamahima424@yahoo.com

Copyright: () the author(s), publisher and licensee Medip Academy. This is an open-access article distributed under the terms of the Creative Commons Attribution Non-Commercial License, which permits unrestricted non-commercial use, distribution, and reproduction in any medium, provided the original work is properly cited.

\begin{abstract}
Background: The coronavirus disease 2019 (COVID-19) is caused by the severe acute respiratory syndrome coronavirus 2 (SARS-CoV-2). It is well accepted that pregnant women are at increased risk of infections, morbidity from known respiratory viruses like H1N1, varicella, influenza. COVID-19, a virus from the same family poses a greater and influential risk to the health of our mothers and their babies. Raised concerns of pregnant women, being physiologically immunocompromised with associated comorbidities like hypertension, diabetes, heart disease, anemia is very challenging for the obstetrician to conquer.

Methods: We tested 405 pregnant women for PCR SARS CoV-2 during the pandemic out of which 59 pregnant women turned out to be positive, and were included in the study analysis. These women had singleton live pregnancy beyond 37 weeks and opted for in patient management. Study participants did not have any known obstetric complications.

Results: $81 \%$ of women were delivered by cesearean section, indication being premature rupture of membranes and anhydramnios in $45 \%$ of women reflecting the infective etiology of the disease. $60 \%$ women were asymptomatic, yet positive for the disease. Community spread was seen in $75 \%$ of the women. No ICU admissions were recorded.

Conclusions: The substantial impact on the vulnerable groups like pregnancy has necessitated need for further studies and research and to build more service models as frontline obstetric COVID health care workers.
\end{abstract}

Keywords: Corona virus, Covid-19, Perinatal period, Pregnancy

\section{INTRODUCTION}

Coronavirus disease 2019 was at first documented in Wuhan, China in December 2019. It expanded rapidly with increase in cases and deaths globally. Limited data is available about coronavirus disease 2019 during pregnancy. ${ }^{1}$ The viral infection caused by Covid 19 has expanded globally rapidly with a basic reproduction number (Ro) of 2-2.5, meaning that 2-3 persons will be infected from an identified patient. ${ }^{2}$ Pregnant women are more susceptible to infections especially when cardiorespiratory system is affected due to physiological and mechanical changes of pregnancy. This can lead to rapid progression to respiratory failure in pregnant women. ${ }^{3}$ During pregnancy there is a switch from Th1 cytokine profile to T-helper 2 (Th2) profile. This leads to immunosuppression and protects the fetus, but makes the mother more vulnerable to viral infections.

Currently the primary epidemiologic risk factors for coronavirus disease 2019 is close contact with infected individuals within 14 days of symptom onset. Data 
suggests an incubation period of $\sim 5$ days (range, 2-14 days). ${ }^{1}$

We have scrutinized the incidence, clinical presentation and maternal-fetal complications in our study and have attempted to understand the clinico-epidemiological framework of the disease, thereby preventing the flux of complications for our moms-to-be!!

According to our internal guidelines formulated by the ICMR (Indian Council and Medical Research), we at Bharati Hospital and Research Centre have initiated Covid testing within 5 days of expected date of delivery.

Our study is proposed to find out incidence of Covid 19 disease during pregnancy and its effects on the maternal and fetal outcome in the Indian setting.

Aim of the study was to evaluate epidemiological and clinical characteristics of Covid 19 disease in mother and newborn in perinatal period.

Objectives of study was to estimate incidence of Covid 19 disease in low risk pregnant women during perinatal period. To evaluate clinical presentation of Covid 19 disease in pregnancy. To study the maternal and fetal complications of Covid 19 disease in perinatal period

\section{METHODS}

\section{Methodology}

Despite the large and rapidly rising cases of coronavirus disease and resulting deaths, there is limited data available about the clinical characteristics of the pregnant women and the disease. The changing presentation of covid 19 virus is astounding and breathtaking.

Study Type: Prospective observational study.

Study Place: Bharati Vidyapeeth Medical College and Research Centre, Pune.

Study Period: June 2020 - December 2020.

Selection Criteria: All pregnant patients, who tested positive with PCR testing for SARS-CoV-2 virus, with singleton live pregnancy beyond 37 weeks, opting for in patient management with no known obstetric complications delivering in Bharati Hospital.

\section{Procedure details}

We have extracted information retrospectively from the labour records of Bharati Vidyapeeth Medical College and Research Centre, Pune over a stretch of 7 months. From June 2020 till December 2020, a robust screen of 405 deliveries were compiled, all suspected and nontested. Records of all pregnant patients, who tested positive with PCR testing for SARS-CoV-2 virus, with singleton live pregnancy beyond 37 weeks, opting for in patient management with no known obstetric complications delivering in Bharati Hospital were selected. These women were further evaluated regarding epidemiological, clinical, laboratory characteristics, treatment and outcomes of pregnancy. Women presenting with preterm labour, twin pregnancy, or having obstetric complications like abruption, placenta previa, eclampsia, HELLP, ARDS, jaundice, thromboembolic disease, severe anemia, cardiac disease or any other debilitating illness were excluded.

\section{Statistical analysis}

Data was entered in Microsoft Excel spreadsheets and analysed using percentages and proportions..

\section{RESULTS}

Table 1: Parity of Covid positive patients.

\begin{tabular}{|lll|}
\hline Parity & n & Percentage \\
\hline Primigravida & 25 & 42.4 \\
\hline Multigravida & 34 & 57.6 \\
\hline Total & 59 & 100 \\
\hline
\end{tabular}

$\mathrm{n}=$ no. of patients

There were 59 patients analyzed among the sum total of 405 deliveries conducted in the study period, $\sim 42 \%$ of these being primigravida and $58 \%$ being multigravidas (Table 1) with median age of 30 , interquartile range of 23- 37 years. In our study, there were $81.4 \%$ Cesarean deliveries. Remaining $18.6 \%$ were conducted through vaginal route (Table 2).

Table 2: Mode of delivery of Covid positive patients.

\begin{tabular}{|lll|}
\hline Mode of Delivery & n & Percentage \\
\hline Cesarean section & 48 & 81.4 \\
\hline Vaginal & 11 & 18.6 \\
\hline Total & 59 & 100 \\
\hline
\end{tabular}

$\mathrm{n}=$ no. of patients

Table 3: Indication of LSCS.

\begin{tabular}{|lll|}
\hline Indication & n & Percentage \\
\hline Fetal distress & 18 & 30.5 \\
\hline Cephalopelvic disproportion & 6 & 10.2 \\
\hline Anhydramnios & 10 & 17.0 \\
\hline $\begin{array}{l}\text { Premature rupture of } \\
\text { membranes }\end{array}$ & 17 & 28.8 \\
\hline Previous LSCS & 8 & 13.5 \\
\hline Total & 59 & $\sim 100$ \\
\hline
\end{tabular}

$\mathrm{n}=$ no. of patients

$30.5 \%$ of cesarean section were due to fetal distress, $10.2 \%$ due to cephalopelvic disproportion, $45.8 \%$ had origin to the infective etiology, indication being anhydramnios or PROM (premature rupture of 
membranes) which could have a probable relation to the increased susceptibility for viral infection. Remaining $13.8 \%$ were obstetric indication for previous LSCS. (Table 3).

Amongst the following, 61\% of the study population was asymptomatic during the isolation period, with $39 \%$ individuals bearing symptoms, mostly mild, not worsening in the perinatal course (Table 4).

Table 4: Presence of symptoms in Covid positive patients.

\begin{tabular}{|lll|}
\hline Symptomatology & n & Percentage \\
\hline Present & 23 & 39 \\
\hline Absent & 36 & 61 \\
\hline Total & 59 & 100 \\
\hline
\end{tabular}

$\mathrm{n}=$ no. of patients

There were no maternal HDU/ ICU admissions recorded in view of pulmonary deficiency caused by SARS CoV-2 virus. Gravid breathlessness was dealt conservatively. No oxygen requirements were noted.

Majority of the patients presented with antepartum diagnosis. To date, about $79 \%$ of individuals were diagnosed antepartum with $21 \%$ of patients diagnosed post-partum. This finding is governed by the regulatory policy of our institution for planned antenatal covid RTPCR testing 5 days prior to expected date of delivery. This mandated policy execution has enabled us to diagnose the asymptomatic crowd and thereby promoting toward the safety of our health workers.

About $47.9 \%$ of symptomatic women had complaints of myalgia and anosmia, $30.5 \%$ were febrile, $13 \%$ had headache associated with myalgia and loose stools and 2 patients came with frank breathlessness, on exertion with on and off sore throat (Table 5).

Table 5: Symptoms of Covid positive patients.

\begin{tabular}{|lll|}
\hline Symptoms & n & Percentage \\
\hline Myalgia anosmia & 11 & 47.9 \\
\hline Fever & 7 & 30.5 \\
\hline Headache loose stool & 3 & 13.0 \\
\hline Breathlessness & 2 & 08.6 \\
\hline Total & 23 & 100 \\
\hline
\end{tabular}

$\mathrm{n}=$ no. of patients

The epidemiological characters were coupled with history of travel in hotspot areas within 15 days of positive report (as labelled by Pune Municipal Corporation) in $15.2 \%$ of women, $10.2 \%$ had history of close contacts.

This affirmation was patient dependent and could not be evaluated completely due to social stigmatization in revealing the disease.
Owing to the laboratory investigations performed in admitted patients, lymphopenia was seen in $37.2 \%$ of individuals (22 out of 59) whereas raised D-dimer was seen in $57.6 \%$ (34 out of 59) individuals of cases in relation to the reference values followed in our labs.*

*Laboratory investigations with reference values.

\begin{tabular}{|ll|}
\hline Parameters & Normal Values \\
\hline D dimer & Up to $243 \mathrm{ng} / \mathrm{L}$ \\
\hline C- reactive protein & $2-8 \mathrm{mg} / \mathrm{L}$ \\
\hline LDH (Lactate dehydrogenase) & $230-460 \mathrm{IU} / \mathrm{L}$ \\
\hline Ferritin & $4.6-204 \mathrm{ng} / \mathrm{ml}$ \\
\hline
\end{tabular}

Women with raised D dimer, were administered Injectable low molecular weight Heparin $0.6 \mathrm{mg}$ twice a day by subcutaneous route and 12 women out of 34 had prolonged treatment with Injection LMWH based on consultation with hematology unit.

Table 6: Epidemiological characteristics of covid positive patients.

\begin{tabular}{|lll|}
\hline $\begin{array}{l}\text { Epidemiological } \\
\text { characteristics }\end{array}$ & n & Percentage \\
\hline $\begin{array}{l}\text { Travel to hotspot areas with } \mathbf{1 5} \\
\text { days of presentation }\end{array}$ & 9 & 15.2 \\
\hline $\begin{array}{l}\text { H/O contact with Covid } \\
\text { positive individual }\end{array}$ & 6 & 10.2 \\
\hline Community spread & 44 & 74.6 \\
\hline Total & 59 & 100 \\
\hline
\end{tabular}

$\mathrm{n}=$ no. of patients

\section{DISCUSSION}

\section{Diagnosis and approach}

Reverse transcriptase polymerase chain reaction assay is the current gold standard for detecting SARS- Cov-2 from respiratory specimens in patients with a sensitivity of $70 \% .^{3}$

Protocol says to reconsider COVID testing if the clinical suspicion arises with initial negative swab. Chest imaging can aid in confirmation. There are multiple challenges due to physiological immunocompromise and gravid uterus. Difficulty in regard to mechanical ventilation poses a threat for anesthetics and obstetricians. Prone ventilation has been adopted to be able to improve oxygenation in such a setting. ${ }^{3}$

Similarly, use of medications is a commotion filled thought and perhaps the hesitation comes for safety of the fetus and its side effects. This can lead to difficult decisions and to overlook maternal interest over fetal interest. Thus, need to expansive studies for further probing. 


\section{Intervention - cesarean or vaginal?}

Most of the deliveries were performed by Cesarean section. Recommendations for cesarean delivery during covid-19 mostly are related to common obstetric indications like fetal distress, previous LSCS, preeclampsia etc. There is a no clear evidence that cesarean section is protective. On other side, vaginal delivery is not contraindicated in Covid-19 patients.

\section{Physiological dilemma or pathological outcome!!}

The reduced immunity and physiological changes in respiratory system like decreased functional residual volumes, diaphragm elevation during pregnancy may lead to increased susceptibility to viral infections. In SARS and MERS, up to 35- 41\% of pregnant patients required mechanical ventilation. The mortality and morbidity was as high as 18 and $25 \%$ in these cases. ${ }^{1}$ In contrast, the majority of reported cases overall and as shown in our study, covid-19 infection has shown mild or asymptomatic course of disease with few cases requiring HDU admission, pertaining to high risk monitoring for pulmonary immunocompromise or any postoperative obstetric indication. This is ascertained to be proven.

\section{Vertical transmission}

There is no concrete evidence about the in-utero transmission of SARS CoV-2 virus. None of the intrauterine transmission were reported in our study. As a protocolized approach, babies from Covid positive are tested for SARS CoV-2 virus at 48 hour of life.

\section{Thromboprophylaxis}

There are emerging reports of increased incidence of both venous and arterial thromboembolism in patients diagnosed with COVID-19 infection due to excessive inflammation, hypoxia, immobilization and diffuse intravascular coagulation. ${ }^{4}$ Anticoagulant treatment with low molecular weight heparin has been associated with improved prognosis in patients with COVID-19 patients, stratified by repeat $\mathrm{D}$ dimer values. ${ }^{5}$

Use of Injection LMWH was based on individualized basis, particularly in women presenting with mild symptoms or none. RCOG recommends that all pregnant women admitted with COVID 19 infection should receive prophylactic LMWH unless birth is expected within 12 hours. $^{6}$

\section{Labour protocol}

All women in labour were monitored by PPE (Personal protective equipment) Continuous fetal monitoring was done for symptomatic patients. Delivery is conducted with limited exposure but with the capacity to involve emergency obstetric and neonatal facilities for resuscitation and intubation. ${ }^{6}$

\section{Breastfeeding}

Breast milk is not believed to be an agent of COVID 19 transmission. A facemask is recommended to be worn while breastfeeding with a dedicated breast pump for every individual. ${ }^{3}$ If expressed, no need for pasteurization to be done. ${ }^{3}$

Limitations: Less sample size of study has offered fallacious percentages on the incidence. This area needs more exploration with multitude of pregnant women to be a part of study.

Advantages: Though the data and resources were limited, a comprehensive analysis of our study data in relation to perinatal outcome, clinical presentation and disease severity is well illustrated.

\section{CONCLUSION}

We believe that these findings have important implications on public health both due to varied disease presentation, and the concern of perinatal outcome. Given this information, a pregnant women should be considered as vulnerable population for this menacing virus clawing the health system from both sides, demanding the clinicians to be cognizant to this group and manage accordingly. We have understood that the true impact of virus over the maternal morbidity and mortality will be evident after a certain while.

\section{Funding: No funding sources}

Conflict of interest: None declared

Ethical approval: The study was approved by the Institutional Ethics Committee

\section{REFERENCES}

1. Yu N, Li W, Kang Q, Xiong Z, Wang S, Lin X, et al. Clinical features and obstetric and neonatal outcomes of pregnant patients with COVID-19 in Wuhan, China: a retrospective, single-centre, descriptive study. The Lancet Infectious Diseases. 2020.

2. Dashraath P, Jeslyn WJ, Karen LM, Min LL, Sarah L, Biswas A, et al. Coronavirus disease 2019 (COVID-19) pandemic and pregnancy. American journal of obstetrics and gynecology. 2020.

3. Ryean GA, Purandare NC, McAuliffe FM, Hod M, Purandare CN. Clinical update on COVID-19 in pregnancy: A review article. J Obstetr Gynaecol Res. 2020.

4. Klok FA, Kruip MJ, Van der Meer NJ, Arbous MS, Gommers DA, Kant KM. Incidence of thrombotic complications in critically ill ICU patients with COVID-19. Thrombosis research. 2020.

5. Tang N, Bai H, Chen X, Gong J, Li D, Sun Z. Anticoagulant treatment is associated with decreased mortality in severe coronavirus disease 2019 patients with coagulopathy. J Thrombosis Haemostasis. 2020;18(5):1094-9. 
6. Royal College of Obstetricians \& Gynaecologists. Coronavirus (COVID-19) infection in pregnancy. Information for healthcare professionals. Version 8. 2020 .
Cite this article as: Dabhadkar SV, Taralekar VS, Arya MR, Barsode SD, Kale PS. Evaluation of clinico-epidemiological factors and outcome of COVID-19 disease in perinatal period. Int J Reprod Contracept Obstet Gynecol 2021;10:1515-9. 